
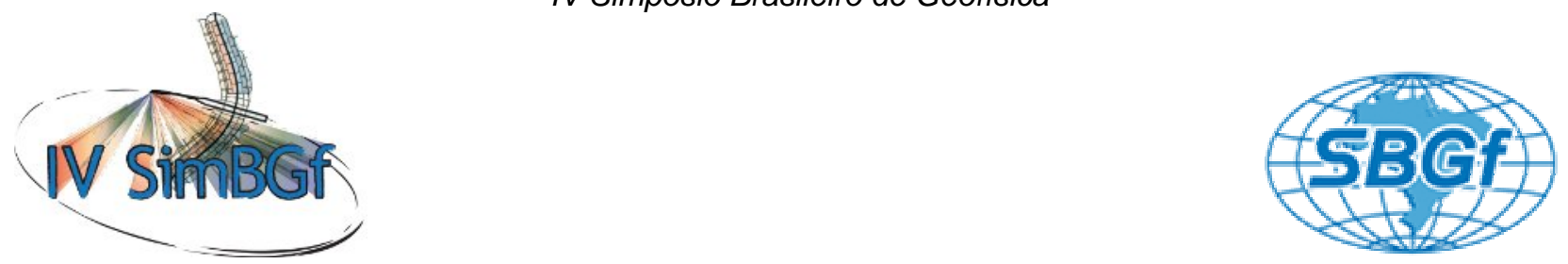

\title{
INVESTIGAÇÕES GEOFÍSICAS GPR NO CEMITÉRIO DE XAMBIOÁ (TOCANTINS): PALCO DE INUMAÇÕES NA ÉPOCA DA GUERRILHA DO ARAGUAIA, ESTADOS DO PARÁ E TOCANTINS
}

CASTELO BRANCO, Raimundo Mariano Gomes (1); PEDROSA JÚNIOR, Nilo Costa (1); BORGES, Welitom Rodrigues (2); BLUM, Marcelo de Lawrence Bassay (3); RUSSO, Daniel (3)

(1) Geofísica - Universidade Federal do Ceará, (2) Universidade de Brasília, (3) Departamento de Polícia Federal

Copyright 2010, SBGf - Sociedade Brasileira de Geofísica

Este texto foi preparado para a apresentação no IV Simpósio Brasileiro de Geofísica, Brasília, 14 a 17 de novembro de 2010. Seu conteúdo foi revisado pelo Comitế Técnico do IV SimBGf, mas não necessariamente representa a opinião da SBGf ou de seus associados. É proibida a reprodução total ou parcial deste material para propósitos comerciais sem prévia autorização da SBG.

\section{Resumo}

Durante os meses de junho, julho e agosto de 2010 foram realizados diversos trabalhos de aquisição de dados GPR na região de Xambioá no Estado do Tocantins. Os trabalhos de aquisição de dados estiveram centrados na área do Cemitério Municipal daquela cidade, onde diversas informações colhidas pelo GTT (Grupo de Trabalho Tocantins) apontavam para a presença de corpos de pessoal envolvido na conhecida Guerrilha do Araguaia, movimento combatido pelo exercito a partir do ano de 1972, nas regiões de fronteira entre os estados do Pará, Maranhão e Tocantins. Neste trabalho foram selecionadas 6 Linhas de aquisição GPR no interior do Cemitério de Xambioá, com extensões variando entre 6 e 15 metros, uso de sistema GPR SIR 3000 , antena com freqüência centrada de $400 \mathrm{MHz}$ e demais acessórios. Entre essas linhas, apenas uma delas não havia nenhuma evidencia de túmulos, e as outras 5 foram realizadas em locais antigos do cemitério, onde as elevações em barro, típicas dos cemitérios da região, já não mais existiam (exceção feita a uma linha). A prospecção direta de anomalias GPR em uma das linhas revelou a presença de corpos em caixões.

\section{Introdução}

As pesquisas com sistemas de radar de penetração no solo - GPR com objetivos forenses têm sido utilizadas em diversas partes do mundo. O principal objetivo neste estudo de caso é o imageamento continuo da subsuperfície e em alta resolução com vistas à detecção de anomalias no sinal GPR que possam corresponder a inumações de guerrilheiros no Cemitério de Xambioá no Estado de Tocantins, envolvidos no evento da Guerrilha do Araguaia, por volta dos anos de 1972 e 1974.

\section{Metodologia Geral e Problema Investigado}

O problema aqui investigado está relacionado ao evento conhecido como Guerrilha do Araguaia acontecido, fundamentalmente, entre os anos de 1972 e 1974 na região, genericamente conhecida como Alto Araguaia, envolvendo a região de fronteira entre os estados do Pará, Maranhão e Tocantins, ambos situados no norte do Brasil. Cerca de 2 anos atrás o Ministério da Defesa formou o Grupo de Trabalho Tocantins (GTT) com o objetivo de busca e resgate de corpos de militares e guerrilheiros mortos na "Guerrilha do Araguaia".

A área indicada e selecionada para aplicação da tecnologia GPR corresponde à área interna do Cemitério Municipal da cidade de Xambioá conforme mostra a figura de localização (Figura 1). Nesta pesquisa foi utilizado um sistema de Radar de Penetração no Solo (GPR) fabricado pela empresa GSSI americana modelo SIR 3000. A antena de freqüência centrada de $400 \mathrm{MHz}$ acoplada a um odômetro, ambos também da GSSI, foi utilizada nas aquisições aqui apresentadas. Na Figura 3 observa-se o sistema de aquisição apresentado um momento de coleta de dados em um dos locais no interior do Cemitério de Xambioá.

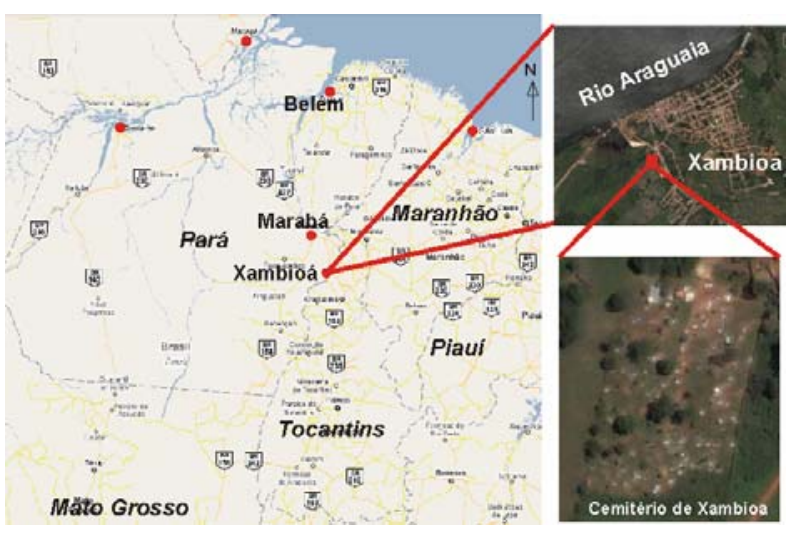

Figura 1 - Localização geográfica da região estudada neste trabalho, Cemitério Publico de Xambioá no Estado do Tocantins, às margens do Rio Araguaia.

Os dados aqui apresentados foram adquiridos em 6 locais diferentes no interior do Cemitério de Xambioá: na realidade 5 deles utilizados para parametrizações e, conseqüentemente, avaliações das respostas de eventuais alvos característicos de inumações. As áreas foram selecionadas levando em consideração o fato de serem antigas e não apresentarem mais vestígios de elevações comuns a túmulos naquela região. As 
elevações às quais estamos referindo são como aquela apresentada na figura 2 ao longo da Linha 4 . Túmulos abandonados com pelo menos mais de 5-10 anos não mais apresentam estas características. Por outro lado, a Linha 0 foi aquela fruto real de campanha geofísica prospectiva, inclusive com aquisição $3 \mathrm{D}$ em duas orientações. Para ela apresenta-se aqui apenas uma das seções 2D que foi adquirida, processada, interpretada e alvo de investigação direta. A figura 2 mostra em detalhe fotografias com a indicação em perspectiva das 6 seções adquiridas, fazendo atenção para a Linha 0 , a que foi alvo de investigações diretas e comprovação de anomalias procuradas. Vale-se ressaltar que apenas esta área foi objeto de autorização judicial para a investigação direta, uma vez que se trata de um Cemitério Publico.

$\mathrm{Na}$ Figura 3, se encontram listados todos os dados técnicos gerais e detalhados, para todas as 6 linhas. Correspondem aos dados de posicionamento (coordenadas geográficas UTM), cotas de inicio e final das linhas e suas respectivas extensões bem como Datum utilizado.
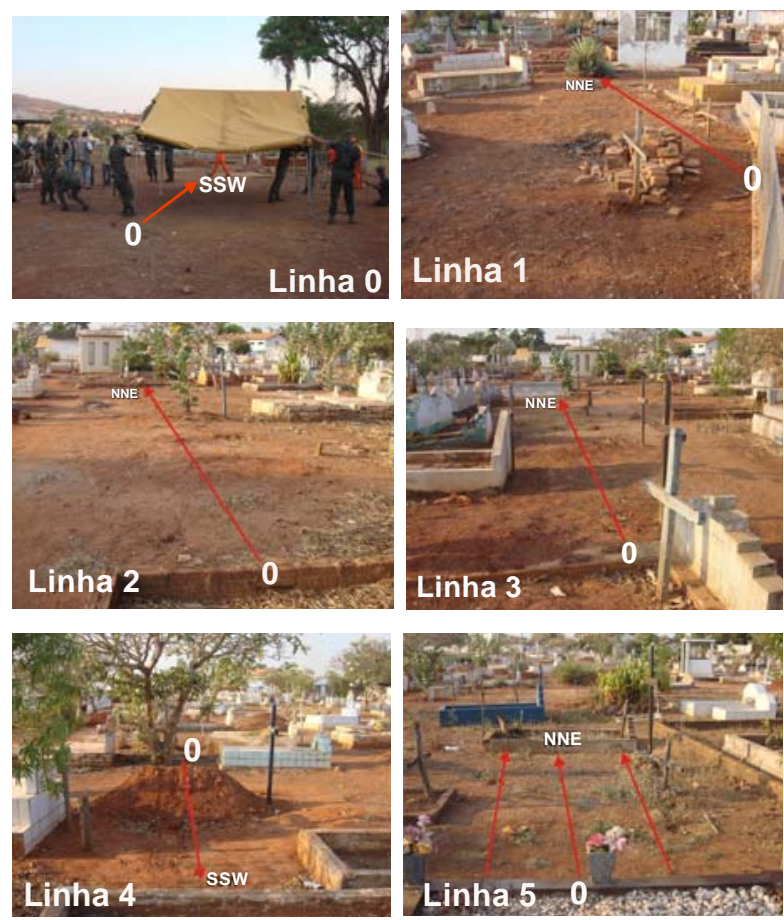

Figura 2 - Posição das 6 Linhas GPR (Linhas 0 a 5) adquiridas no interior do Cemitério de Xambioá.

\begin{tabular}{|c|c|}
\hline $\begin{array}{l}\text { LINHA } 2 \\
\text { Coordenadas do Inicio }\end{array}$ & $\begin{array}{l}\text { LINHA } 3 \\
\text { Coordenadas do Inicio }\end{array}$ \\
\hline $772233 \quad 9290203$ & $\begin{array}{l}\text { Coordenadas do Iniclo } \\
772228\end{array}$ \\
\hline $\begin{array}{l}\text { Coordenadas do Final } \\
772236 \quad 9290216 \\
\text { Cotas do Inicio e Fim }\end{array}$ & $\begin{array}{l}\text { Coordenadas do Final } \\
772231 \quad 9290210 \\
\text { Cotas do Inicio e Fim }\end{array}$ \\
\hline $\begin{array}{l}134,064 \quad 134,087 \\
\text { Extensão da Linha } \\
14 \text { m etros }\end{array}$ & $\begin{array}{l}\text { Cotas do Inicio e Fim } \\
134,088 \quad 133,959 \\
\text { Extensão da Linha } \\
15,2 \text { metros }\end{array}$ \\
\hline $\begin{array}{l}\text { Datum } \\
\text { SIRGAS 2000, ZONA22 SUL,UTM }\end{array}$ & $\begin{array}{l}\text { Datum } \\
\text { SIRGAS 2000, ZONA22 SUL,UTM }\end{array}$ \\
\hline $\begin{array}{l}\text { LINHA } 4 \\
\text { Coordenadas do Inicio } \\
772241 \quad 9290206 \\
\text { Coordenadas do Final }\end{array}$ & $\begin{array}{l}\text { LINHA } 5 \\
\text { Coordenadas do Inicio } \\
772244 \quad 9290176\end{array}$ \\
\hline $\begin{array}{l}772240 \quad 9290201 \\
\text { Cotas do Inicio e Fim }\end{array}$ & $\begin{array}{l}\text { Coordenadas do Final } \\
772245\end{array}$ \\
\hline $\begin{array}{l}\text { Cotas do Inicio e Fim } \\
134,190 \quad 134,182 \\
\text { (meio } 134,184 / 134,721 / 134,185 \text { ) }\end{array}$ & $\begin{array}{l}\text { Cotas do Inicio e Fim } \\
134,324 \\
134,341\end{array}$ \\
\hline $\begin{array}{l}\text { Extensão da Linha } \\
5,2 \text { m etros }\end{array}$ & $\begin{array}{l}\text { Extensáo da Linha } \\
5 \text { metros }\end{array}$ \\
\hline 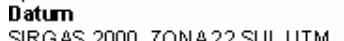 & $\begin{array}{l}\text { Datum } \\
\text { SIRGAS 2000, ZONA.22 SUL,UTM }\end{array}$ \\
\hline
\end{tabular}

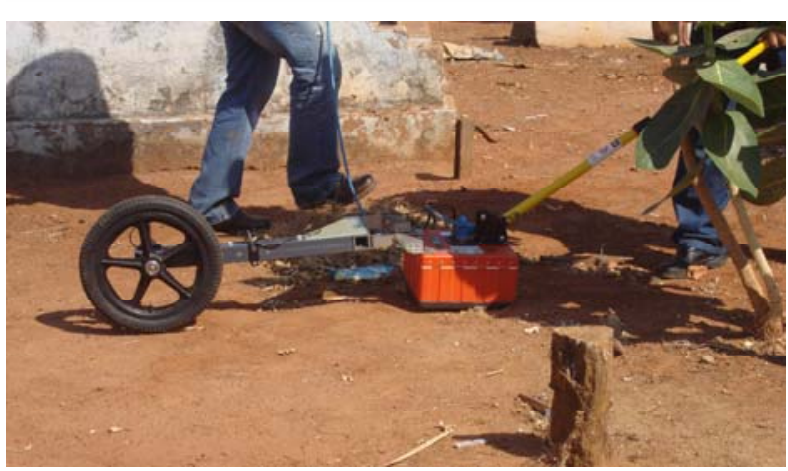

Figura 3 - Dados gerais de coordenadas, cotas e extensão das linhas de GPR adquiridas e fotografia de aquisição GPR ao longo de uma das linhas.

Os dados foram processados no software ReflexW, versão 5.0 (Sandmeier, 2009). A rotina de processamento consistiu em conversão de formato do arquivo, ajuste do tempo zero, filtros temporal (dewow e passa-banda), ganho (decaimento de energia), migração no domínio do tempo ( $f k$ migration - Stolt) e conversão de tempo de propagação em profundidade utilizando a velocidade constante calculada pelo teste do ajuste hiperbólico. Este ajuste foi efetuado utilizando uma picareta metálica como alvo a 0,50 metros de profundidade no solo presente no Cemitério de Xambioá. A figura 4 mostra uma imagem do ajuste realizado na parametrização da velocidade da onda do meio.

LINHA O
Coordenadas do Inicio
$772206 \quad 9290303$
Coordenadas do Final
$772200 \quad 9290280$
Cotas do Inicio e Fim
$135,402 M 34,671$
Extensão da Linha
6 metros
Datum
SIRGAS 2000, ZONA.22 SUL, UTM

\author{
LINHA 1 \\ Coordenadas do Inicio \\ $772217 \quad 9290242$ \\ Coordenadas do Final \\ $772217 \quad 9290249$ \\ Cotas do Inicio e Fim \\ $134,056 \quad 134,241$ \\ Extensão da Linha \\ 8 metros \\ Datum \\ SIRGAS 2000, ZONA22 SUL,UTM
}




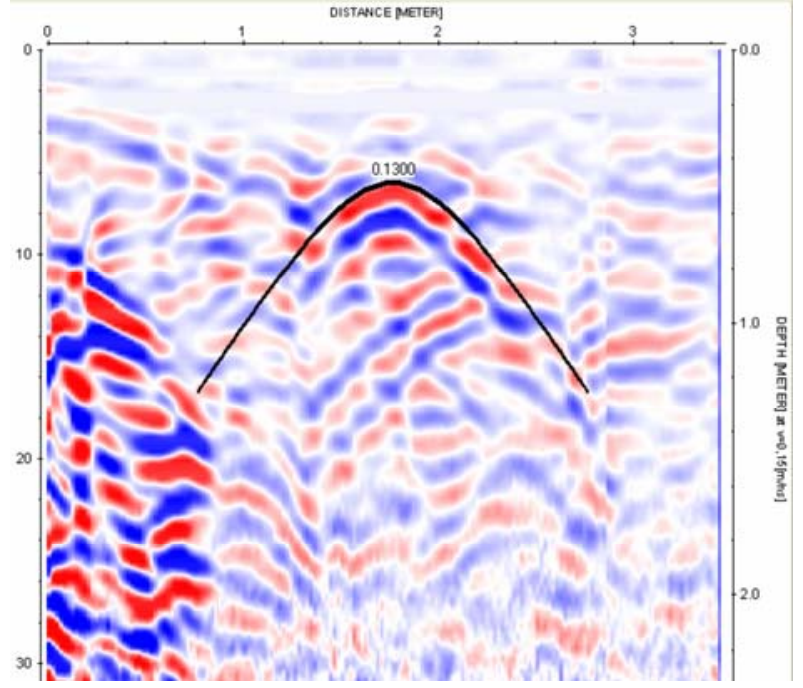

Figura 4 - Parametrização de velocidade através de ajuste da hipérbole com material metálico enterrado a 0,5m no solo da área.

\section{Resultados}

Uma série de anomalias foram detectadas através do processamento realizado e se encontram mostradas na figura 5(A a F). Geralmente as anomalias correspondem a feições planares ou suavemente onduladas com amplitude do sinal elevada, representadas pelas tonalidades mais escuras. Na seqüência de figuras elas estão apontadas por círculos pretos e pelas setas vermelhas. Outras zonas anômalas aparecem, mas são devidas a fatores espúrios ao interesse da pesquisa (blocos de rochas, elevações na superfície, raízes de plantas, outros artefatos superficiais). Alguns refletores horizontalizados correspondem a horizontes concrecionários do solo raso mais resistivo. Na figura $5 \mathrm{~A}$, na posição de 4,7 metros foi perfurados no terreno, uma vala quadrada de 2 por 1,2 metros com 1,10 de profundidade, como mostra a figura 6 , quando foi encontrado um caixão com restos mortais de um adulto. Este material foi imediatamente periciado pelos médicos legistas do IML e da Policia Federal de Brasília.

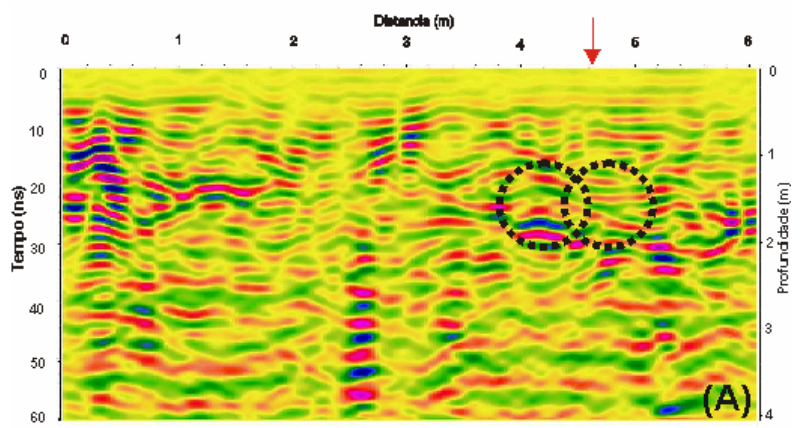

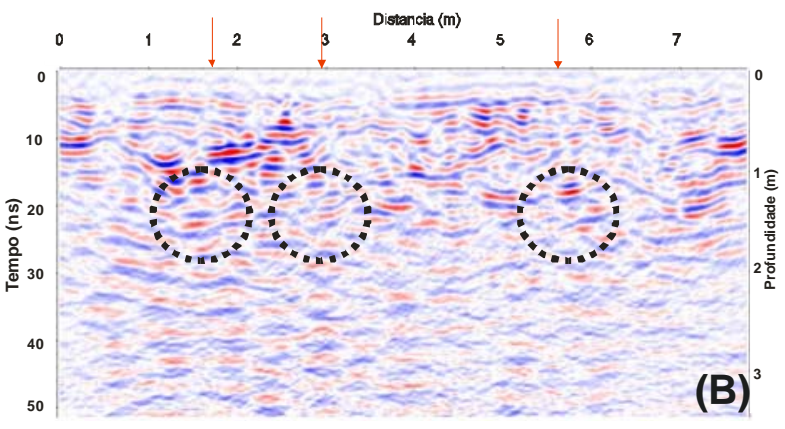
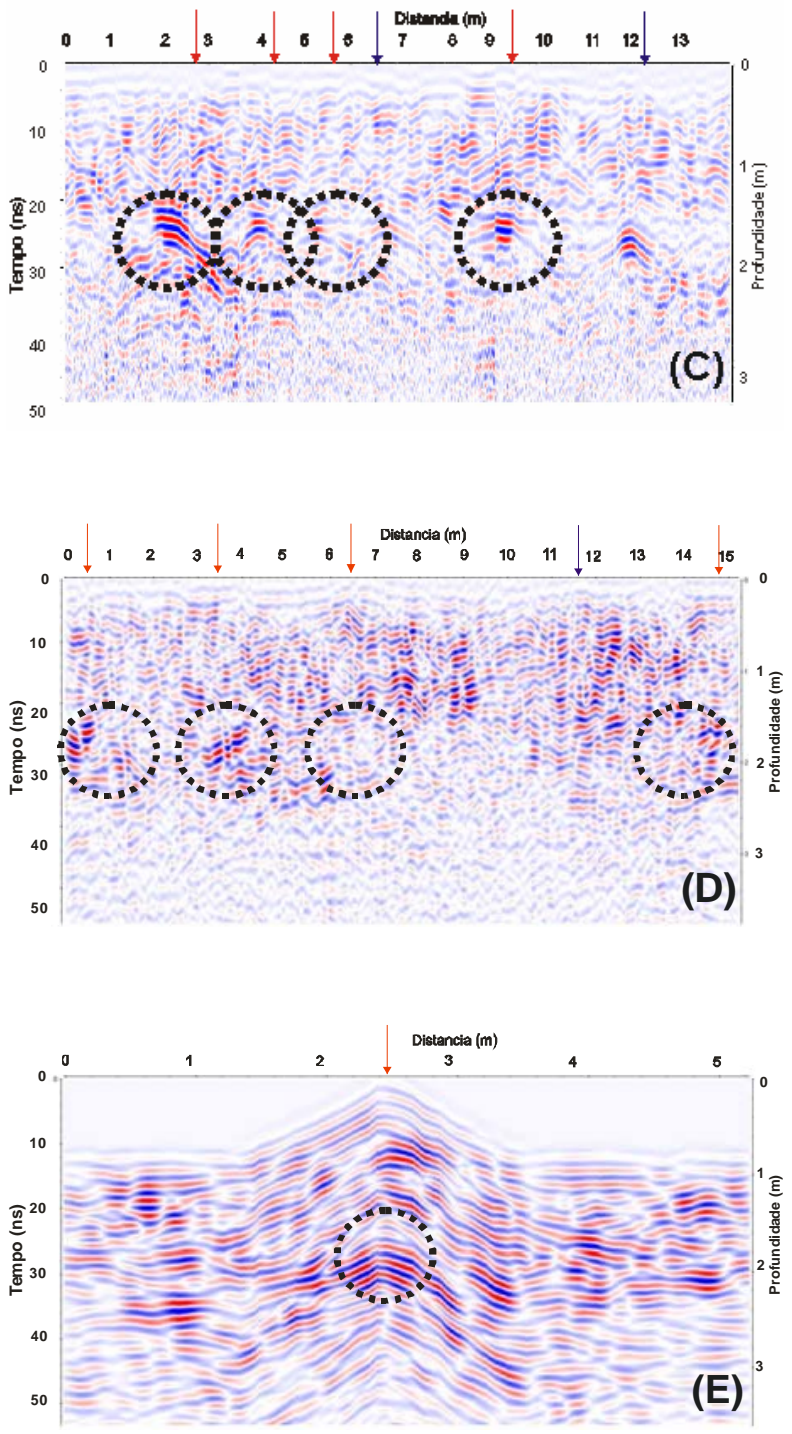


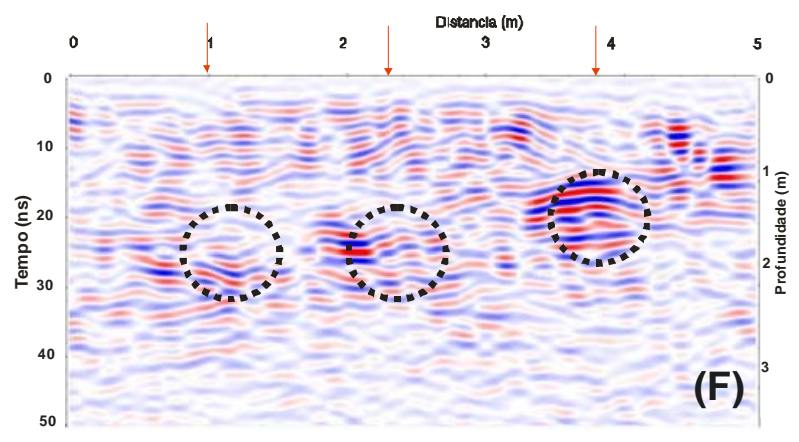

Figura 5 - Indicações de anomalias após o processamento e interpretação dos dados GPR ao longo das 6 Linhas ( $A$ a $F$ ou Linhas 0 a 5). As setas vermelhas indicam anomalias importantes e os círculos pretos a visualização em profundidades. Setas azuis indicam possibilidades de outras anomalias. Aqui estão indicadas as anomalias comprovadas por presença de túmulos antigos sem vestígios de elevações. Notar que apenas a Linha 4 (figura 5E) apresenta a elevação de tumulo mais recente e que teve elevação corrigida. $O$ alvo prospectado diretamente foi o indicado na Linha $0(5 A)$.

De modo geral, o material encontrado trata-se de fragmentos de crânio, mandíbula, maxilar e dentes. Valese ressaltar que ao lado deste caixão foi encontrado um outro com restos mortais de uma criança. Isso é bastante sugestivo com a presença daquelas duas anomalias indicadas na figura $5 \mathrm{~A}$.

As outras Linhas GPR processadas que se encontram na figura $5 \mathrm{~B}$ a $5 \mathrm{~F}$ foram realizadas, conforme mostra a figura 2, em áreas no interior do Cemitério de Xambioá com presença de inumações. Como se pode examinar as anomalias correspondentes são bastante claras e se encontram em profundidades bastante semelhantes aquelas normalmente presentes em covas de cemitérios.

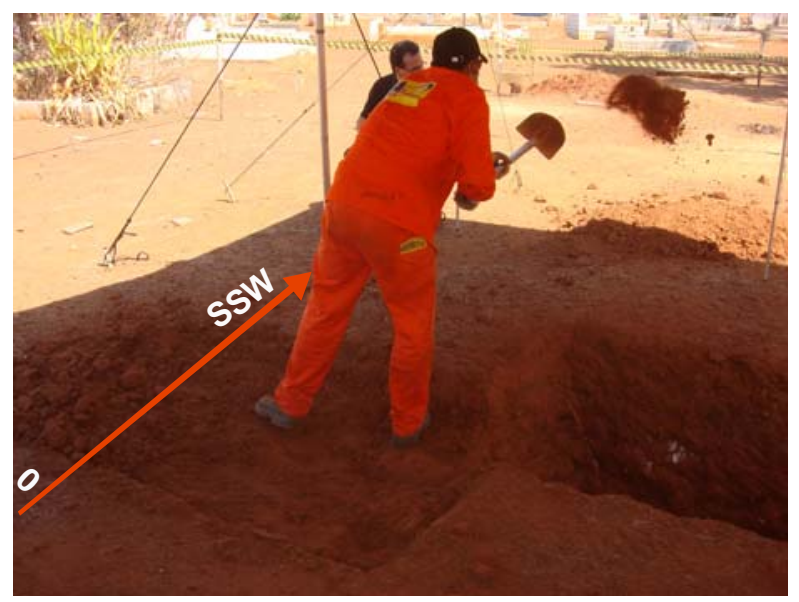

Figura 6 - Fotografia ilustrando a perfuração de alvos indicados pela interpretação das linhas GPR.
Na figura 7 encontra-se uma fotografia tomada após o cuidadoso trabalho de escavação dos médicos legistas do IML e da Polícia Federal de Brasília, comprovando a presença da inumação subjacente à anomalia geofísica GPR interpretada na Linha 0 (figura 5A). Já a figura 8 mostra o material retirado e periciado pelos técnicos na porção central da figura 7 .

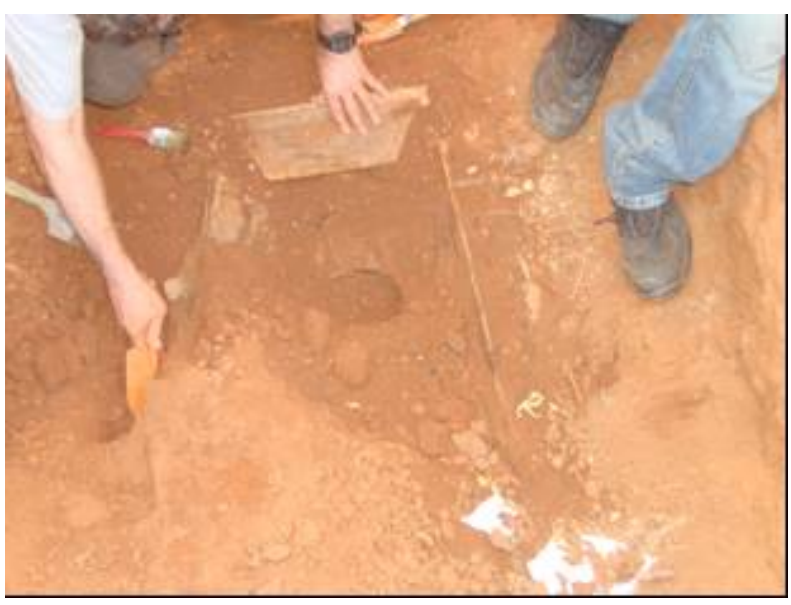

Figura 7 - Fotografia ilustrando uma das anomalias detectada na Linha 0 e correspondente a um caixão com restos mortais. Ao centro posição do crânio.

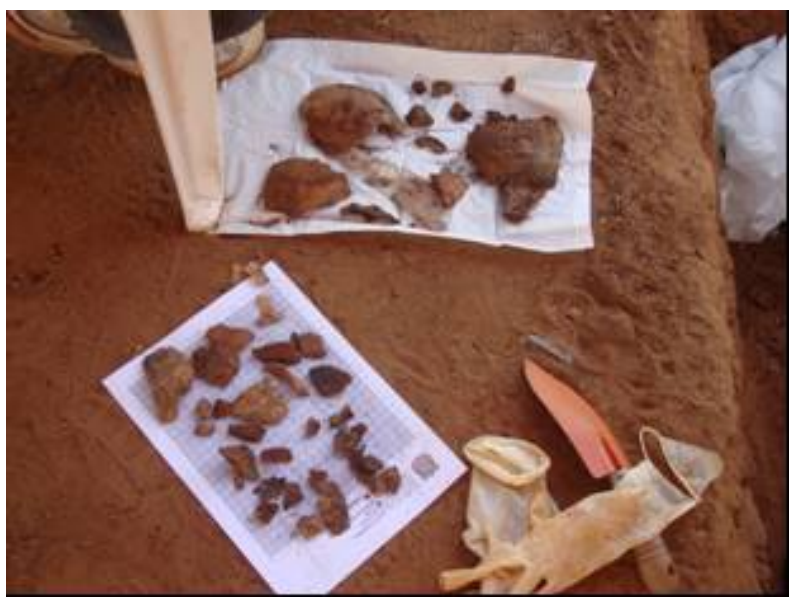

Figura 8 - Fotografia ilustrando material encontrado na posição central da fotografia 8.

\section{Conclusões}

O uso do GPR na detecção de anomalias possivelmente relacionadas a inumações no Cemitério Municipal de Xambioá se mostrou eficaz. As parametrizações realizadas ao longo de 5 linhas são importantes no sentido de melhor diagnosticar o "formato" geral das anomalias do sinal GPR para a antena de $400 \mathrm{MHz}$, eventualmente, correspondentes a inumações. O aprofundamento das questões relacionadas com diferenciação de outras anomalias merece maior 
investimento em processamento bem como o uso, já iniciado, de antenas de maior resolução e maior freqüência. A presença da anomalia GPR e sua investigação direta em profundidade mostraram-se como importante meio de investigação para o Grupo de Trabalho Tocantins formado pelo Ministério da Defesa; infelizmente, o achado (s) não deve $(\mathrm{m})$ corresponder a guerrilheiros mortos no evento da Guerrilha do Araguaia.

\section{Referências Bibliográficas}

SANDMEIER, K.J., 2009. REFLEX, Sandmeier Software, Alemanha. 